\title{
Activation Analysis Applied to High Purity Metals and Alloys
}

\author{
M. Fedoroff, J.C. Rouchaud and P. Benaben* \\ Centre National de la Recherche Scientifique, Centre d'Etudes de Chimie Métallurgique, \\ 15 rue Georges Urbain, 94407 Vitry, France \\ * Ecole des Mines, 42023 Saint-Etienne, France
}

\begin{abstract}
The application of activation analysis to high-purity metals is reviewed. The advantages, disadvantages and causes of error are discussed. Examples of applications are given and discussed, using neutron, photon and charged particle activation. The main advantage of activation analysis is to avoid and to remove contaminations. This leads to high accuracy even for very low concentrations. Finally, the main characteristics of new mass spectrometric methods versus activation analysis are discussed.
\end{abstract}

\section{INTRODUCTION}

In recent years, investigations of high-purity metals have joined the field of industry and are no longer devoted only to knowledge of the basic properties of solid state materials. Analytical methods must follow this development. They must be accurate and sensitive, but, at the same time they must be applied to a larger number of samples and must be more comprehensive concerning the number of determined impurities. They have also to be less time-consuming and, also, conform to all criteria of quality assurance. The purpose of this paper is to review the present state of activation analysis, as a method very well suited to ultra-trace analysis, and to try to place it in the new context of high-purity metal studies. Since the first use af activation analysis by Hevesy and Levi [1] in 1936, this technique has become a unique tool for all problems dealing with trace element analysis. Only recently, several new methods, mainly based on mass spectrometry, have also reached the capability to detect low levels of elements. What is the place of activation analysis in this new context ?

\section{PRINCIPLES OF ACTIVATION ANALYSIS}

Activation analysis belongs to the nuclear methods of analysis. The main characteristic of these methods is that they use the properties of the nuclei of the elements, while "classical" methods use the properties of the electrons. Therefore, the measured analytical signal does not depend on the chemical state of the first element and is not sensitive to its chemical "environment".

The sample is irradiated with appropriate particles or radiations, in order to produce an interaction with the nuclei of the selected elements and to generate a signal, specific to the element and quantitatively related to its concentration. From this basic principle, two types of nuclear methods may be considered. In "prompt" methods, the emitted signal is measured during the irradiation. This signal may be the particles diffused by elastic or inelastic interactions, or particles or radiations emitted by nuclear reactions. In contrast, in "delayed" nuclear methods, the measurement is performed after the irradiation has been stopped. Activation analysis belongs to the second type of nuclear method: during the irradiation period, nuclear reactions are produced, then the radioactivity of radio-isotopes produced during the irradiation time is measured.

The main steps of an activation analysis procedure is summarized in Fig. 1. The "cooling" time is used (when needed) in order to eliminate the radioactivity of short-lived isotopes which may be produced from some major elements of the sample. Etching is a very important step of the analysis : it eliminates the contaminated superficial layer of the sample (see later, advantages of activation analysis). Chemical separations are used to eliminate some radio-elements which may disturb the detection of other radioelements which are at much lower levels. In many cases, it is possible to perform purely instrumental 
analyses. However, chemical separations are easy to use (no contamination, use of carriers, see below) and may considerably lower the detection limits of some elements. In the majority of cases, the radioactivity measurements are performed by $\gamma$-spectrometry : the resolution of modern detectors insures selective detection of radio-isotopes. Computing is the last step of the analysis; it performs the numerical treatment of the $\gamma$-spectra and the calculation of the concentrations.

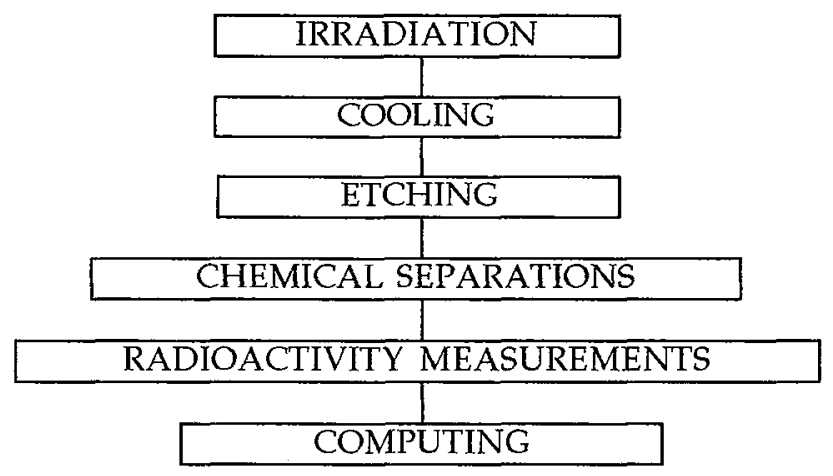

Figure 1 : Main steps used in an activation analysis procedure

Irradiation sources are summarized on Fig. 2. Neutrons produced in the nuclear reactors are the main particles used in activation analysis. Reasons for this are the high fluxes available, the possibility of long irradiation times, the high number of elements which may detected by this method. The availability is explained by the fact that, in many reactors, activation analysis is only a secondary utilization of the reactor. The majority of elements can be determined by neutron irradiation. However, several elements cannot be detected by neutrons : elements lighter than sodium (except nitrogen [3]), and some heavier elements, such as lead.

Irradiation by charged particles ( $\left.p, d, t,{ }^{3} \mathrm{He},{ }^{4} \mathrm{He}, ..\right)$ gives access to the determination of all elements not detected by neutrons, and is also an alternative method for elements detected by neutrons. Irradiation with $\gamma$-photons is a good method for determining $\mathrm{C}, \mathrm{N}, \mathrm{O}, \mathrm{F}$ and many other elements.

- NEUTRONS

-REACTORS

-GENERATORS (cyclotrons, $14 \mathrm{MeV}$ )

-ISOTOPIC SOURCES

- CHARGED PARTICLES

-VAN DE GRAAFF
-CYCLOTRONS

-VAN DE GRAAFF
-CYCLOTRONS thermal neutrons

epithermal neutrons

fast neutrons

४ PHOTONS

-LINEAR ACCELERATORS
-BETATRONS, MICROTRONS

Figure 2 : Particles and radiations used in activation analysis, and their main sources

Examples of the application of these methods to high purity methods will be given $(\S 6)$. 


\section{ADVANTAGES}

\subsection{High sensitivity}

This advantage is first connected with the fact that measurements are based on the detection of each individual event which constitutes a radioactive disintegration. This fact is also associated with the high probability (cross section) of many nuclear reactions, to the high available fluxes of particles and finally to the absence of contamination (see $\$ 3.2$ ).

\subsection{Absence of contamination}

Some classical methods have very low theoretical detection limits. However, the practical detection limits are much higher, because of contamination. In activation analysis, it is really possible to achieve the theoretical limits. We have to distinguish between two types of contamination.

The first type is contamination occurring after irradiation: this contamination does not disturb the analysis as it is not radioactive. It is not necessary to use high-purity chemicals or clean rooms. On the contrary, in the case of chemical separations, it is useful to "contaminate" the sample by adding non radioactive "carriers", in order to control the separation yield better and not to lose very small quantities by sorption phenomena. Of course, contamination by the same radioactive isotopes as those used in the analysis must be avoided.

The second type is superficial contamination of the sample, produced before and during irradiation. This contamination may be removed by adequate etching performed after irradiation. The newly formed superficial contamination is no longer radioactive and does not affect the analysis. Of course, the sample analysed must be a solid, and its core must not have been contaminated by unexpected diffusion.

In other words, the concept of "blank" does not appear in activation analysis. This advantage is specific to this method and makes it a unique tool for ultra-trace analysis.

\subsection{Easy standardization}

As the radioactivity produced does not depend on the chemical state, standardization is facilitated. Any chemical forms of elements may used as standards. There is no error related to the chemical environment of the elements. This is also a great advantage contributing to the accuracy of the method.

\subsection{Multi-element analysis}

Using $\gamma$-spectrometry, multi-element analysis is possible. Generally, about 40 elements can be determined after a single irradiation with reactor neutrons.

\subsection{Direct measurement of radioactivity}

Using $\gamma$-spectrometry and choosing appropriate irradiation conditions, instrumental analysis without chemical separation is possible in many cases.

\subsection{Easy chemical separations}

If, however, some radiosiotopes have a rather high radioactivity and disturb the detection of other radioelements, chemical separation has to be used. But in activation analysis, such separations are greatly facilitated by the use of "carriers" and by the absence of contamination, as already pointed out.

\subsection{Low cost counting equipment}

Compared to optical or mass-spectrometry, $\gamma$-spectrometry uses rather low cost systems. A complete system, including a Ge detector and a personal computer may be purchased for less than $\$ 40,000$. 


\section{DISADVANTAGES}

\subsection{Availability of irradiation sources}

The main disadvantage is the necessity of having access to rather heavy irradiation sources. This aspect limits the number of laboratories able to use activation analysis.

\subsection{Delay of answer}

This delay occurs mainly from the fact that the irradiation source is generally not situated in the laboratory using it for analysis, and also from the long measurement times used for low radioactivities.

\subsection{Variation of detection limits from one element to another}

One characteristic of nuclear reactions is the variation of cross sections from one isotope to another, leading to a variation in detection limits. It is impossible to perform a comprehensive analysis using only one type of irradiation. As already pointed out, reactor neutron irradiation leads to a multi-element analysis, but some elements are excluded. Other means of irradiation have to be used in order to extend the analysis to these elements.

\subsection{Safety problems}

Obtaining the necessary authorizations, the knowledge of handling radio-elements and the use of control equipment may be a constraint. However, the radioactivity levels used in activation analysis are generally low.

\section{MAIN SOURCES OF ERROR}

\subsection{Interference}

Interference may result either from two different nuclear reactions leading to the same isotope from different elements, or interfering $\gamma$-rays. In both cases, the interferences are rather limited in number, well known and can be calculated prior to the analysis.

\subsection{Counting losses, statistics}

These classical errors are well known. Considerable progress has been achieved recently in the correction of losses during measurement of high disintegration rates.

\subsection{Self-shielding}

In a limited number of cases, for samples whose major elements have very high cross-sections for the irradiating particles, an attenuation of the irradiation flux occurs in the sample. For samples whose geometries are not too complicated, this attenuation can easily be calculated.

\subsection{Ineffective surface etching}

As already mentioned, one of the advantages of activation analysis is the possibility of removing the surface contaminated layer, without further pollution. This removal must be really effective. In certain cases it is not. Such effects may be explained by phenomena such as non-homogeneous superficial dissolution, redeposition or the presence of a persistent porous oxide layer. We studied in detail the problem of iron etching [2]. When iron is etched in a $\mathrm{HF}-\mathrm{H}_{2} \mathrm{O}_{2}$ polishing bath, there is a permanent oxide layer; iron dissolves by diffusion through this layer, which keeps all the contaminants in it. This problem can be solved by alternating this bath with another bath containing $6 \mathrm{M} \mathrm{HCl}$, which has the property of dissolving the oxide layer together with its contaminants. 


\section{EXAMPLES OF ANALYSES}

Some examples will be given in order to illustrate the use of different irradiation sources for the analysis of high purity metals. Results of the analysis of aluminium refined by zone-melting are given in Table1.

Table 1 Multi-element analysis of zone-refined aluminium by thermal neutron activation analysis (NAA) and proton activation analysis (PAA), with $10 \mathrm{MeV}$ and $15 \mathrm{MeV}$ protons. Concentrations are given in $\mu \mathrm{g} \cdot \mathrm{g}^{-1}$.

\begin{tabular}{|c|c|c|c|}
\hline & NAA & PAA $10 \mathrm{MeV}$ & PAA $15 \mathrm{MeV}$ \\
\hline$\overline{\mathrm{Ag}}$ & 0.004 & $\leq 0.07$ & $\leq 0.05$ \\
\hline As & $\leq 0.00002$ & $\leq 0.02$ & \\
\hline $\mathrm{Au}$ & $\leq 0.000002$ & $\leq 0.4$ & $\leq 0.6$ \\
\hline $\mathrm{B}$ & & $\leq 0.1$ & $\leq 0.05$ \\
\hline $\mathrm{Ba}$ & $\leq 0.05$ & $\leq 17$ & \\
\hline $\mathrm{Br}$ & $\leq 0.0001$ & $\leq 0.01$ & \\
\hline $\mathrm{Ca}$ & & $\leq 0.03$ & $\leq 0.0045$ \\
\hline $\mathrm{Cd}$ & $\leq 0.007$ & $<0.015$ & $\leq 0.006$ \\
\hline $\mathrm{Co}$ & $\leq 0.0004$ & & \\
\hline $\mathrm{Cr}$ & 0.026 & 0.027 & \\
\hline $\mathrm{Cu}$ & 0.0055 & $\leq 0.05$ & $\leq 0.03$ \\
\hline $\mathrm{Fe}$ & $\leq 0.1$ & $\leq 0.03$ & \\
\hline $\mathrm{Ga}$ & 0.0012 & $\leq 0.01$ & $\leq 0.02$ \\
\hline $\mathrm{Ge}$ & $\leq 0.06$ & $\leq 0.008$ & \\
\hline $\mathrm{Hg}$ & $\leq 0.3$ & & \\
\hline $\mathrm{Hf}$ & 0.0021 & & \\
\hline I & & $\leq 0.02$ & $\leq 0.0015$ \\
\hline Ir & $\leq 0.0001$ & $\leq 0.65$ & \\
\hline In & $\leq 0.002$ & $\leq 1.3$ & \\
\hline $\mathrm{La}$ & $\leq 0.00004$ & & \\
\hline$\tilde{\mathrm{Li}}$ & & $\leq 0.01$ & $\leq 0.05$ \\
\hline $\mathrm{Mn}$ & 0.021 & & \\
\hline Mo & 0.013 & $\leq 0.015$ & $\leq 0.010$ \\
\hline $\mathrm{Na}$ & $\leq 0.003$ & & \\
\hline $\mathrm{Nb}$ & & $\leq 0.09$ & \\
\hline $\mathrm{Pb}$ & & $\leq 0.4$ & \\
\hline $\mathrm{Pd}$ & $\leq 0.006$ & $\leq 0.07$ & $\leq 0.01$ \\
\hline $\mathrm{Pt}$ & $\leq 0.001$ & $\leq 0.1$ & $\leq 0.07$ \\
\hline $\mathrm{Rb}$ & & $\leq 0.02$ & \\
\hline $\mathrm{Re}$ & & $\leq 0.35$ & \\
\hline $\mathrm{Rh}$ & & $\leq 16$ & $\leq 5.7$ \\
\hline $\mathrm{Ru}$ & $\leq 0.001$ & $\leq 0.02$ & \\
\hline $\mathrm{Sb}$ & $\leq 0.000001$ & $\leq 0.025$ & \\
\hline $\mathrm{Sc}$ & 0.0018 & & \\
\hline Sn & $\leq 0.1$ & $\leq 0.07$ & $\leq 0.01$ \\
\hline $\mathrm{Se}$ & $\leq 0.001$ & $\leq 0.02$ & \\
\hline $\mathrm{Sr}$ & & $\leq 0.04$ & \\
\hline $\mathrm{Te}$ & $\leq 0.004$ & $\leq 0.015$ & $\leq 0.03$ \\
\hline $\mathrm{Tl}$ & & $\leq 0.15$ & \\
\hline $\mathrm{Ti}$ & & 0.01 & \\
\hline $\mathrm{V}$ & & $\leq 0.02$ & $\leq 0.005$ \\
\hline W & 0.021 & $\leq 1$ & \\
\hline Y & & $\leq 0.002$ & \\
\hline $\mathrm{Zn}$ & 0.07 & 0.15 & \\
\hline $\mathrm{Zr}$ & & $\leq 0.015$ & \\
\hline
\end{tabular}


In this example, about thirty elements were determined by reactor neutron activation analysis (NAA) and instrumental $\gamma$-spectrometry. This analysis was completed by a proton activation analysis (PAA) and instrumental $\gamma$-spectrometry. Two energies of protons were tested in order to study the influence of energy on the detection limits. As may be seen, NAA leads to the lower detection limits for elements as Au, As, La... But it cannot determine elements such as $\mathrm{B}, \mathrm{Ca}, \mathrm{Li}, \mathrm{Pb}$.. PAA determines these elements. A comparison may be performed, when both methods could detect the same elements. Agreement is good for Cr. There is a discrepancy for $\mathrm{Zn}$, perhaps due to an unexpected interference in PAA. NAA and PAA are good complementary methods and are able to characterize high-purity aluminium. More than forty elements were successfully determined with limits of detection less than $0.1 \mu \mathrm{g} . \mathrm{g}^{-1}$.

Table 2 Determination of some elements in high-purity aluminium and iron by thermal neutron activation analysis (NAA) and in high-purity cobalt and tantalum by proton activation analysis (PAA). Only some selected elements are given.

Concentrations are given in $\mu \mathrm{g} \cdot \mathrm{g}^{-1}$.

\begin{tabular}{|c|c|c|c|c|}
\hline & $\begin{array}{c}\text { Al } \\
\text { NAA }\end{array}$ & $\begin{array}{c}\mathrm{Fe} \\
\mathrm{NAA}\end{array}$ & $\begin{array}{c}\text { Co } \\
\text { PAA }\end{array}$ & $\begin{array}{c}\text { Ta } \\
\text { PAA }\end{array}$ \\
\hline$\overline{\mathrm{Ag}}$ & $\leq 0.0003$ & & $\leq 0.06$ & \\
\hline As & $\leq 0.0005$ & 0.001 & $\leq 0.09$ & $\leq 0.4$ \\
\hline Co & 0.0007 & 0.03 & - & \\
\hline $\mathrm{Cr}$ & 0.024 & $\leq 0.3$ & $\leq 0.04$ & $\leq 0.01$ \\
\hline $\mathrm{Cu}$ & 0.0016 & 0.8 & 3.3 & $\leq 0.05$ \\
\hline $\mathrm{Fe}$ & $\leq 0.03$ & - & 5.0 & $\leq 0.4$ \\
\hline $\mathrm{Ga}$ & 0.0006 & & $\leq 0.02$ & \\
\hline $\mathrm{Mn}$ & 0.0055 & 0.03 & & \\
\hline Mo & 0.002 & 0.2 & $\leq 0.03$ & 2.1 \\
\hline $\mathrm{Nb}$ & & & $\leq 0.2$ & 39 \\
\hline $\mathrm{Sb}$ & $\leq 0.0001$ & 0.0001 & $\leq 0.2$ & $\leq 0.9$ \\
\hline $\begin{array}{l}\mathrm{Sc} \\
\mathrm{Zn}\end{array}$ & $\begin{array}{l}0.00038 \\
\leq 0.005\end{array}$ & & $\leq 1.5$ & $\leq 0.09$ \\
\hline
\end{tabular}

Table 2 illustrates another complementary aspect of NAA and PAA. NAA is well suited to the analysis of aluminium, as the major isotopes formed from the metal have a short half-life, and after about one hour of cooling, the radioactivity is negligeable. In the case of iron, the half-life is 45 days and therefore, NAA is less favourable but still possible as the radioactivity produced from the matrix element is rather small. In the case of cobalt and tantalum, NAA produces high long-lived radioactivity and cannot be used. PAA is a good alternative method : if the iradiation energy is well chosen, the radioactivity produced from the matrix elements is negligeable and an instrumental multi-element analysis is possible.

Table 3. Examples of the determination of carbon and nitrogen in iron, steel and silicon by $\gamma$ photon activation and neutron activation through the nuclear reactions :

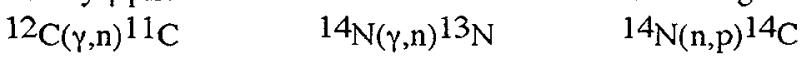

Concentrations are given in $\mu \mathrm{g} \cdot \mathrm{g}^{-1}$

\begin{tabular}{cccc}
\hline Samples & $\begin{array}{c}\text { Carbon } \\
\text { photons }\end{array}$ & $\begin{array}{c}\text { Nitrogen } \\
\text { photons }\end{array}$ & $\begin{array}{c}\text { Nitrogen } \\
\text { neutrons }\end{array}$ \\
\hline "OH" iron & $121 \pm 5$ & & \\
"OH" iron H2 treated & $0.25 \pm 0.07$ & & \\
"JM" iron & $3.5 \pm 0.7$ & $0.7 \pm 0.4$ & \\
"JM" iron H2 treated & $0.07 \pm 0.03$ & $\leq 0.15$ & \\
zone-refined iron & $0.2 \pm 0.1$ & $0.5 \pm 0.2$ & $0.8 \pm 0.2$ \\
zone-refined iron H2 treated & $0.07 \pm 0.03$ & & \\
standard steel $\left(\mathrm{N}=65 \mu \mathrm{g} \cdot \mathrm{g}^{-1}\right)$ & & & $68 \pm 5$ \\
metallurgical silicon & $27 \pm 3$ & $16 \pm 1$ & $14 \pm 1$ \\
zone-refined silicon & $\leq 0.03$ & $\leq 0.4$ & $\leq 0.08$ \\
\hline
\end{tabular}


Table 3 gives a comparison of the use of photon and neutron irradiation for the determination of light elements. Carbon was determined by photon activation, while nitrogen was determined by both methods. The neutron activation method for nitrogen [3], is a good alternative for laboratories with access to a reactor. The results illustrate the purification effect of annealing under hydrogen for iron, and of zone refining for silicon.

Table 4. Examples of the determination of carbon, oxygen and sulphur in some high purity metals by charged particles or $\gamma$ photon activation. The particle is indicated in each case.

Concentrations are given in $\mu \mathrm{g} \cdot \mathrm{g}^{-1}$

\begin{tabular}{cccccc}
\hline Metal & Carbon & Carbon & Oxygen & Oxygen & Sulphur \\
& $\gamma$ & ${ }^{3} \mathrm{He}$ & ${ }^{3} \mathrm{He}$ & ${ }^{3} \mathrm{~T}$ & $\mathbf{1}_{\mathrm{p}}$ \\
\hline $\mathrm{Co}$ & 2.8 & & 0.2 & & $\leq 0.4$ \\
$\mathrm{Mo}$ & & 0.2 & 0.5 & 0.3 & \\
$\mathrm{~W}$ & & 0.1 & 0.02 & & \\
$\mathrm{Fe}$ & & 0.3 & 0.4 & & \\
\hline
\end{tabular}

Table 4 gives examples of the use of photon or charge particles irradiation for the determination of carbon, oxygen and sulphur, for several high-purity metals.

\section{CONCLUSION}

Activation analysis is a method very well suited to the detection of low levels of impurities, as it may achieve detection limits less than $1 \mathrm{ng} \cdot \mathrm{g}^{-1}$ for many elements. The main advantage of this method is its high accuracy even for very low concentrations. As we have already explained, the origin of this advantage is the possibility of avoiding and removing contamination.

Activation analysis must now be compared to new, non nuclear methods, which, potentially, have also low limits of detection. The most interesting ones are based on mass spectrometry : Inductively Coupled Plasma Mass Spectrometry (ICPMS), Glow Discharge Mass Spectrometry (GDMS), Laser Ionization Mass Spectrometry (LIMS), Resonance Ionization Mass Spectrometry (RIMS).

The most attractive advantages of these methods are : the potential sensitivity of mass spectrometry, the relatively uniform sensitivity leading to a comprehensive multi-element analysis. Except for ICPMS, where the sample is dissolved, the other MS methods can be applied directly to the solid. The equipment is expensive, but the possibility of locating it in your own laboratory insures independence from irradiation sources and quick answers.

The main disadvantage of these methods is their sensitivity to contamination effects. Special and expensive precautions have to be taken in order to minimize them. Other problems arise from inteference, coming from pluri-element ions and from standardization. The best way to improve the accuracy of these methods is to perform comparative analyses using several different methods. Activation analyses may be used as a reference method. We have already begun such comparisons [4]. They need to be enlarged on the international scale. Another useful approach is the development and use of reference materials.

\section{References}

[1] Hevesy G. and Levi H., Math. Fys. Medd. 14 (1936) 34.

[2] Delmas R., Fedoroff M. and Revel G. : J. Trace Microprobe Tech. 2 (1984) 67.

[3] Rouchaud J. C. and Fedoroff M. : Anal. Chem., 58 (1986) 108.

[4] Fedoroff M. and Rouchaud J. C., UPHM-94, Kitakyushu, Japan, 24-27 may 1994, p. 210. 